\title{
A p-loop motif and two basic regions in the regulatory protein GvpD are important for the repression of gas vesicle formation in the archaeon Haloferax mediterranei
}

Institut für Mikrobiologie und Genetik, TU

Darmstadt,

Schnittspahnstr. 10 , D-64287 Darmstadt, Germany

\author{
Felicitas Pfeifer, Jens Zotzel, Brigitta Kurenbach, Richard Röder \\ and Peter Zimmermann
}

Author for correspondence: Felicitas Pfeifer. Tel: +49 6151 162957. Fax: +49 6151162956. e-mail: pfeifer@bio.tu-darmstadt.de

\begin{abstract}
$\Delta \mathrm{D}$ transformants containing all 14 gvp genes of Haloferax mediterranei required for gas vesicle formation except for $\mathrm{gvpD}$ are gas vesicle overproducers $\left(\mathrm{Vac}^{++}\right)$, whereas $\triangle \mathrm{D} / \mathrm{D}$ transformants containing the gvpD reading frame under ferredoxin promoter control on a second construct in addition to $\Delta \mathrm{D}$ did not form gas vesicles $\left(\mathrm{Vac}^{-}\right)$. The amino acid sequence of GvpD indicates three interesting regions (a putative nucleotide-binding site called the p-loop motif, and two basic regions); these were altered by
\end{abstract} mutation, and the resulting $G{ } D_{\text {mut }}$ proteins tested in $\triangle D / D_{\text {mut }}$ transformants for their ability to repress gas vesicle formation. The exchange of amino acids at conserved positions in the p-loop motif resulted in $\mathrm{Vac}^{++} \Delta \mathrm{D} / \mathrm{D}_{\text {mut }}$ transformants, indicating that these $G_{v p D_{\text {mut }}}$ proteins were unable to repress gas vesicle formation. In contrast, a GvpD ${ }_{\text {mut }}$ protein with an alteration of a non-conserved proline in the p-loop region (P41A) was still able to repress. The repressing function of the various GvpD proteins was also investigated at the promoter level of the gvpA gene. This promoter is only activated during the stationary phase, depending on the transcriptional activator protein GvpE. Whereas the $\mathrm{Vac}^{++} \Delta \mathrm{D}$ transformants contained very high amounts of gvpA mRNA predominantly in the stationary growth phase, the amount of this transcript was significantly reduced in the $\mathrm{Vac}^{-}$transformants $\triangle \mathrm{D} / \mathrm{D}$ and

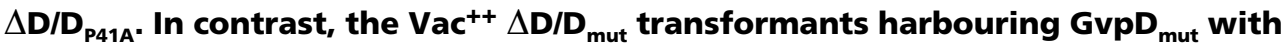
mutations at conserved positions in the p-loop motif contained large amounts of gvpA mRNA already during exponential growth, suggesting that this motif is important for the GvpD repressor function during this growth phase. The GvpD mutants containing mutations in the two basic regions were mostly defective in the repressing function. The $\mathrm{GvpD}_{\text {mut }}$ protein containing an exchange of the three arginine residues 494RRR496 to alanine residues was able to repress gas vesicle formation. No gvpA mRNA was detectable in this transformant, demonstrating that this GvpD protein was acting as a strong repressor. All these results imply that the GvpD protein is able to prevent the GvpE-mediated gvpA promoter activation, and that the p-loop motif as well as the two basic regions are important for this function.

Keywords: halophilic archaea, gas vesicles, repressor, gene regulation 


\section{INTRODUCTION}

The moderately halophilic archaeon Haloferax mediterranei produces gas vesicles during the stationary growth phase when grown in media containing $17-30 \%$ $(\mathrm{w} / \mathrm{v})$ salt, whereas cells grown in $15 \%$ salt media are gas vesicle free (Rodriguez-Valera et al., 1983; Englert et al., 1990). Gas vesicles are watertight, gas-permeable proteinaceous structures that allow organisms such as cyanobacteria or halophilic archaea to float in their watery environment (reviewed by Walsby, 1994). The ribbed envelope is formed by the $7-8 \mathrm{kDa}$ protein GvpA; the GvpC protein is a minor constituent that strengthens the gas vesicle structure and plays a role in shape determination (Hayes et al., 1992; Englert \& Pfeifer, 1993; Halladay et al., 1993; Kinsman et al., 1995; Offner et al., 1996).

Gas vesicle formation of $H f$. mediterranei involves 14 gvp genes located in the so-called mc-vac region $(\mathrm{mc}=$ mediterranei chromosomal) that are arranged as two clusters, namely mc-gvpACNO and, upstream and oppositely oriented, mc-gvpDEFGHIJKLM (Englert et al., 1992a; see Fig. 1). The boundaries of the mc-vac region have been defined by transformation experiments using the $\mathrm{Vac}^{-}$species Haloferax volcanii as recipient (Englert et al., 1992b). Two similar vac regions are found in the extremely halophilic archaeon Halobacterium salinarum PHH1, which contains the socalled p-vac region on plasmid $\mathrm{pHH} 1$, and a second $g v p$ gene cluster named c-vac in the chromosome (Englert et al., 1992a). A vac region almost identical to p-vac has been reported on plasmid pNRC100 of $\mathrm{Hb}$. salinarum NRC-1 (Jones et al., 1991; DasSarma et al., 1994; Ng et al., 1998). The requirement of each gvp gene for gas vesicle formation has been investigated in more detail for both plasmid-encoded vac regions (DasSarma et al., 1994; Offner \& Pfeifer, 1995; Offner et al., 1996, 2000). These studies indicate that $g v p D$ and $g v p E$ encode proteins presumably involved in the regulation of gas vesicle formation.

Two promoters located in front of mc-gvpA and mc$g v p D$ (the $\mathrm{mcA}$ and $\mathrm{mcD}$ promoter) drive the expression of the mc-vac region of $H f$. mediterranei, leading to a complex pattern of transcription (Englert et al., 1992a; Röder \& Pfeifer, 1996). Minor amounts of the $7 \mathrm{~kb}$ mc-gvpDEFGHIJKLM and the $3.0 \mathrm{~kb}$ mc-gvpDEF mRNAs occur together with $2.0 \mathrm{~kb}$ and $1.3 \mathrm{~kb}$ mc-g $v p D$ transcripts during a short period in exponential growth, whereas the mc-gvpACNO cluster encoding the two gas vesicle structural proteins is not expressed at this time (see Fig. 1). During the stationary growth phase the $2.0 \mathrm{~kb}$ mc-gvpD mRNA and large amounts of the $1.3 \mathrm{~kb}$ and $0.45 \mathrm{~kb}$ transcripts occur. Also at this time, the mcgvpACNO cluster is expressed, leading to large amounts of the $0.32 \mathrm{~kb}$ mc-gvpA mRNA and minor amounts of various mc-gvpACNO cotranscripts (Röder \& Pfeifer, 1996). The strong activity of the $\mathrm{mcA}$ and $\mathrm{mcD}$ promoters during the stationary growth phase depends on the transcriptional activator GvpE encoded by the second gene in the mc-gvpD-M gene cluster. The GvpE

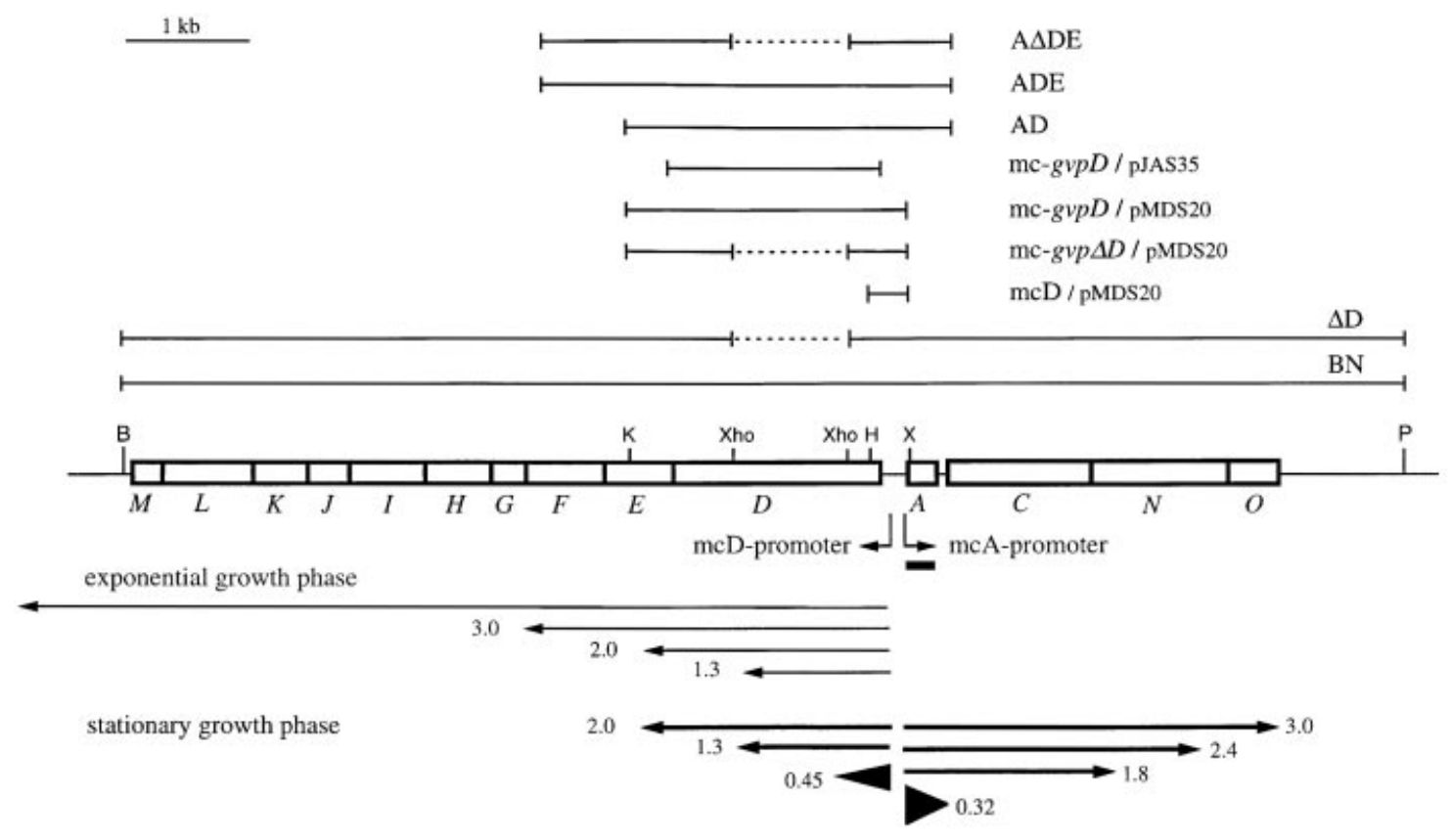

Fig. 1. Genetic map of the mc-vac region in $H f$. mediterranei and schematic representation of the transcripts and constructs used for transformation. The mc-gvp genes are depicted as boxes labelled $A$ and $C$ through $O$. Vertical lines indicate relevant restriction sites used for cloning (B, BamHI; $\mathrm{H}, \mathrm{Hpal} ; \mathrm{K}, \mathrm{Kpnl} ; \mathrm{P}, \mathrm{Pstl} ; \mathrm{X}, \mathrm{Xcml}$; Xho, Xhol). The bar below the mc-gvpA gene represents the probe used for Northern analyses. Arrows below the map indicate the direction and relative strength of transcripts grouped according to their appearance during growth of the culture (Röder \& Pfeifer, 1996). Lines above the map depict the various constructs used for transformation experiments. 
proteins encoded by all three archaeal vac regions resemble a basic leucine zipper protein (Krüger et al., 1998), with structural similarities to eukaryotic gene regulators such as GCN4 in yeast (Ellenberger et al., 1992). In the case of the mc-vac region, the mcA promoter by itself is almost inactive, and only active in a transformant containing mc-gvpA and mc-gvpE (Röder \& Pfeifer, 1996).

Transcription in archaea depends on a single DNAdependent RNA polymerase comprising 12 subunits that are homologous to the subunits of the eukaryotic RNA polymerase II. In addition, the archaeal promoter consists of a TATA box centred around position -28 upstream of the transcription start site, and the initiation of transcription requires the TATA box binding protein TBP and the transcription initiation factor TFB homologous to the eukaryotic transcription factor TFIIB (Hausner et al., 1996; Qureshi et al., 1995; Thomm, 1996). Multiple divergent genes encoding the transcription initiation factor TFB have been identified in $H f$. volcanii (Thompson et al., 1999). A second DNA element (TFB recognition element, BRE) located adjacent to the TATA box is also shared by archaea and eukaryotes (Lagrange et al., 1998; Qureshi \& Jackson, 1998). Despite the eukaryotic RNA polymerase and promoter structure, most archaeal gene regulator proteins are of the bacterial type. Examples are a repressor protein involved in the regulation of nitrogen fixation in Methanococcus maripaludis (Cohen-Kupiec et al., 1997), and the regulator of arginine fermentation in Hb. salinarum (Ruepp \& Soppa, 1996; Soppa et al., 1998). The only example of a transcriptional activator similar to a eukaryotic-type regulator appears to be the basic leucine zipper protein GvpE (Krüger et al., 1998).

In contrast to GvpE, the product of the mc-gvpD gene participates in the repression of gas vesicle formation: $H$ f. volcanii transformants containing an mc-vac region with a deletion in mc-gvpD ( $\Delta \mathrm{D}$ transformants) overproduce gas vesicles $\left(\mathrm{Vac}^{++}\right.$phenotype) in such a way that the discoid $H f$. volcanii cells turn into spheres (Englert et al., 1992b). The addition of the mc-gvpD gene on a second vector construct $\left(\Delta \mathrm{D} / \mathrm{D}_{\text {native }}\right.$ transformant) reduces the amount of gas vesicles to the wildtype level, suggesting a repressor function of GvpD (Pfeifer et al., 1994). Northern analyses demonstrate that $\Delta \mathrm{D}$ transformants contain significantly higher amounts of all mc-vac transcripts (Röder \& Pfeifer, 1996). Since large amounts of the $6 \mathrm{~kb} \mathrm{mc}-g \nu p \Delta \mathrm{D}-\mathrm{M}$ mRNA containing the mc-gvpE reading frame are present, the overproducer phenotype of the $\Delta \mathrm{D}$ transformant could also be the result of an increased amount of GvpE.

The amino acid sequences of GvpD proteins of all three vac regions of halophilic archaea indicate interesting features: these proteins contain near the $\mathrm{N}$-terminus a conserved p-loop motif $\left({ }_{36} \mathrm{LYNGAPGTGKT}_{46}\right)$ found in GTP/ATP-binding proteins such as adenylate kinase, RecA, Ras, G-proteins and elongation factors (Saraste et al., 1990). In these proteins, ATP or GTP is bound in the p-loop sequence, and the $\gamma$-phosphoryl group is hydro- lysed either by the nucleotide-binding protein itself or by an additional enzyme (Smith \& Rayment, 1996; Skovgaard et al., 1998). The conserved amino acid sequence of the classical mononucleotide-binding fold (kinase 1 motif) is GxxGxGKT/S ( $\mathrm{x}=$ any amino acid). The lysine residue binds the negatively charged $\beta$ - and $\gamma$ phosphoryl groups, whereas the serine (or threonine) residue is involved in the magnesium binding (Deyrup et al., 1998). The mutagenesis of one conserved amino acid leads to a reduction in activity, or even to the loss of function (Konola et al., 1994; Skovgaard et al., 1998).

In this study, we investigated the cause of the gas vesicle overproducing phenotype of $\Delta \mathrm{D}$ transformants in more detail. The putative p-loop motif in GvpD was mutagenized and the resulting mutants tested in $\Delta \mathrm{D} / \mathrm{D}_{\text {mut }}$ transformants to detect GvpD mutant proteins that are unable to reduce the amount of gas vesicles. Similar experiments were also employed to investigate the functional importance of two basic regions within GvpD. In addition, the various GvpD mutant proteins were tested for their ability to repress the formation of mc-gvpA mRNA.

\section{METHODS}

Growth of Hf. volcanii. Hf. volcanii WFD11, used for transformation experiments, was obtained from W.F. Doolittle (Halifax, Canada). The Hf. volcanii growth medium contained $3 \mathrm{M} \mathrm{NaCl}, 150 \mathrm{mM} \mathrm{MgSO}, 40 \mathrm{mM} \mathrm{KCl}, 10 \mathrm{nM}$ $\mathrm{MnCl}_{2}, 25 \mathrm{mM}$ Tris/HCl pH 7.2, $0 \cdot 05 \%$ (w/v) $\mathrm{CaCl}_{2}, 0 \cdot 5 \%$ $(\mathrm{w} / \mathrm{v})$ tryptone and $0.3 \%(\mathrm{w} / \mathrm{v})$ yeast extract. Liquid cultures were grown at $37^{\circ} \mathrm{C}$ and 180 r.p.m., whereas colonies were grown on medium solidified with $1.8 \%(\mathrm{w} / \mathrm{v})$ agar at $42{ }^{\circ} \mathrm{C}$.

Transformation of Hf. volcanii WFD11. The $9 \cdot 259 \mathrm{bp} \Delta \mathrm{D}$ construct contains the entire mc-vac region inserted in pWL102, but has incurred a $918 \mathrm{bp} \mathrm{XhoI} \mathrm{deletion} \mathrm{within} \mathrm{the}$ mc-gupD gene (Englert et al., 1992b). The ADE and A $\Delta \mathrm{DE}$ constructs have been previously described (Röder \& Pfeifer, 1996). Hf. volcanii $\Delta \mathrm{D}$ transformants were transformed with different variants of mc-g $v p D$ inserted in pMDS20 (Holmes et al., 1991), or in the expression vector pJAS35 (Pfeifer et al., 1994). The mc-gvpD/pMDS20 construct contained a $2002 \mathrm{bp}$ $X c m I-K p n I$ fragment (see Fig. 1), the mc-gvp $\Delta \mathrm{D}$ construct contained the same fragment except for the $918 \mathrm{bp}$ XhoI deletion, and the $\mathrm{mcD}$ construct carried a $320 \mathrm{bp} \mathrm{XcmI-HpaI}$ fragment containing the $\mathrm{mcD}$ promoter region plus $111 \mathrm{bp}$ of the $5^{\prime}$ part of mc-g $v p D$. The mc-g $v p D / p J A S 35$ construct harboured the mc-gvpD reading frame amplified as a $1651 \mathrm{bp}$ PCR fragment using the primers CCAAAGTGCGTCATCCATGGCCC (positions 4296-4318; NcoI site spanning the ATG start codon underlined) and CCTCGATGAGCGGTACCATCTGTC (positions 5971-5948; KpnI site introduced underlined), and inserted as an NcoI-KpnI fragment in pJAS35. Hf. volcanii transformants containing the entire mcvac region as a BN construct (Englert et al., 1992a) were used as control. Prior to the transformation of Hf. volcanii, each construct was passaged through the Escherichia coli Dam ${ }^{-}$ strain GM1674 (Palmer \& Marinus, 1994) to avoid a halobacterial restriction barrier (Holmes et al., 1991). Transformation was done as previously described (Pfeifer \& Ghahraman, 1993), and transformants were selected on agar plates containing $6 \mu \mathrm{g}$ mevinolin $\mathrm{ml}^{-1}$ (for the selection of $\Delta \mathrm{D}$ in $\mathrm{pWL} 102$ ) and $0 \cdot 2 \mu \mathrm{g}$ novobiocin $\mathrm{ml}^{-1}$ (for the selection of pMDS20 or pJAS35). The presence of the desired constructs in 
Table 1. Oligonucleotides used to amplify and mutagenize mc-gvpD sequences, and resulting mutations in GvpD

\begin{tabular}{|c|c|c|c|}
\hline Name & Oligonucleotide* & Position $†$ & $\begin{array}{l}\text { Mutation } \\
\text { in Gvpd }\end{array}$ \\
\hline $\operatorname{gvpD} / \mathrm{Bam}+\mathrm{Nco}$ & GACCAAAGTGCGGGATCCATG $\underline{G C C C C A C C A A A C C ~}$ & $4294-4327$ & - \\
\hline gvpD/HindIII & 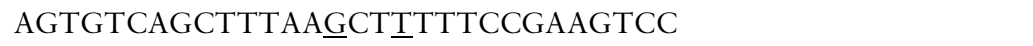 & $6000-5970$ & - \\
\hline MutP1 & CCCGGCGCT $\underline{G C G T T A A C G A G C A G C}$ & $4436-4413$ & G39A \\
\hline MutP2 & CGTCTTTCCĒGTTGCCGGCGCTCC & $4449-4425$ & G42A \\
\hline MutP3 & GAACAGCGTCTTTĒ CCGTTCCCGGG & $4455-4430$ & G44A \\
\hline MutP4 & CGTGAACAGCGTCTㅡTCCCGTTCCGG & $4458-4432$ & K45E \\
\hline MutP5 & CTTTCCCGTTCCCGE्CCGCTCCGTTACG & $4446-4419$ & P41A \\
\hline MutP6 & GAACAGCGTCTTNNCCGTNNCCGGCGCNNCGTTAACGAGCAG & $4455-4414$ & EDD \\
\hline AAAA & 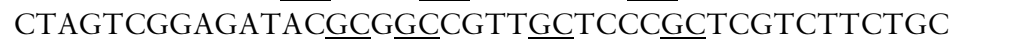 & $4942-4900$ & AAAA \\
\hline AEAE & CTAGTCGGAGATACTCGGCCGTTTCTCCCGCCTCGTCTTCTGC & $4942-4900$ & AEAE \\
\hline 2-AAA & AATACGGACTCCGG $\overline{\overline{C C}} \overline{\overline{A C G C C T} \overline{C T A G T G} \overline{C G} A G A T A C C G G C G C G T}$ & $4965-4921$ & 2-AAA; 2-AAAR \\
\hline 3-AAA & GGAACCGAACTCGCAGCGGCGGCGGACCGCG & $5779-5809$ & 3-AAA; 3-ADA \\
\hline BamD & GTGCGGGATCCATGGCC $\overline{C A} C C$ & $4301-4322$ & - \\
\hline HinD & GAGCCGTTCAAGCTTTCACACCATCTCC & $5938-5964$ & - \\
\hline
\end{tabular}

*Underlined nucleotides indicate mutations compared to the respective m-vac sequence. The start codon (ATG) of the gvpD reading frame is shown in italic.

† The GenBank accession number of the mc-vac sequence is X64701.

each transformant was controlled by Southern analyses using the internal $918 \mathrm{bp}$ Xhol fragment derived from mc-g $v p D$, and vector-specific probes that were produced using either two $0 \cdot 1 \mathrm{~kb}$ SacI fragments derived from the gyrB gene in pJAS35, or an $1.8 \mathrm{~kb}$ EcoRV fragment derived from the HMG-CoA reductase gene in $\mathrm{pWL102}$. Both probes were labelled by the random priming method using the DIG DNA Labeling Kit from Roche.

Site-directed mutagenesis of the mc-gvpD reading frame. The mutations in the mc- $g v p D$ reading frame were achieved by two consecutive PCR reactions, where the product of the first PCR (the 'megaprimer' containing the desired mutation) was used in the second PCR together with a third primer. The sequences of the oligonucleotide primers used for the amplification are given in Table 1 . The wild-type mc-g $\nu p D$ reading frame was amplified using $H f$. mediterranei DNA as template and the oligonucleotides gvpD-Bam $+\mathrm{Nco}$ and gvpD-HindIII as primers. The BamHI site next to NcoI, and the HindIII site near the $3^{\prime}$ terminus, were used to insert the 1681 bp mc-gvpD fragment into the E. coli vector pBluescript.

For the construction of mutations in the p-loop motif the primer gvpD/Bam + Nco was used with one of the oligonucleotides MutP1 through MutP6 (see Table 1) and $H f$. mediterranei DNA as template, resulting in the amplification of the respective $200 \mathrm{bp}$ megaprimer. Each megaprimer was used in a second PCR together with the T7 primer and mc$g v p D$-pBluescript SK + as template for the amplification of the $1.7 \mathrm{~kb}$ mc-gvpD reading frame. For the mutagenesis of the basic region 1 (position 201-215 in the GvpD sequence), different megaprimers were synthesized using the primer gvpD/Bam + Nco together with either the AAAA or the AEAE primer (Table 1), resulting in the amplification of a $649 \mathrm{bp}$ fragment. The oligonucleotide gvpD/Bam + Nco together with primer 2-AAA amplified a $672 \mathrm{bp}$ fragment. The basic region 2 (positions 494-496 in GvpD) is located near the 3'terminus of mc-gvpD and was mutagenized using the primer pair 3-AAA plus gvpD/HindIII, resulting in a $211 \mathrm{bp}$ megaprimer. Each megaprimer was used together with the gvpD/
HindIII primer (in the case of basic region 1), or the $\operatorname{gvpD} / \mathrm{Bam}+\mathrm{Nco}$ primer (in the case of basic region 2 ) for the second PCR that amplified the $1.7 \mathrm{~kb}$ mc-g $v p D$ fragment containing the desired mutations.

The mutated mc-gvpD fragments were cloned as BamHIHindIII fragments into pBluescript and the mutations were confirmed by DNA sequence analyses. Unexpectedly, two additional mutations leading to D2-AAAR instead of D2AAA, and D3-ADA instead of D3-AAA, were observed, most likely due to additional mutations in the oligonucleotides used for PCR. Each mutated mc- $g \nu p D$ reading frame was inserted into the halobacterial expression vector pJAS35 using the $\mathrm{NcoI} / K p n \mathrm{I}$ sites, and used for the transformation of $\mathrm{H} f$. volcanii.

Isolation of RNA from Hf. volcanii and transcript analyses. RNA from $H f$. volcanii transformants was isolated according to the single-step method of Chomczynski \& Sacchi (1987). RNA from transformants in the exponential growth phase was isolated from cultures at $\mathrm{OD}_{600} 0 \cdot 3-0 \cdot 4\left(\mathrm{OD}_{600}\right.$ measurements were made in a Beckman spectrophotometer), whereas RNA from stationary-phase cells was isolated from cultures at $\mathrm{OD}_{600} \geqslant 2$. Northern analyses involved electrophoresis of 5 or $10 \mu \mathrm{g}$ RNA on denaturing, formaldehyde-containing $1.2 \%$ $(\mathrm{w} / \mathrm{v})$ agarose gels, followed by transfer to nylon membranes (Ausubel et al., 1988). Strand-specific RNA probes were synthesized using a $918 \mathrm{bp}$ XhoI fragment derived from mcg $v p D$, or a 367 bp XcmI-EcoRI fragment from mc-g $v p A$ cloned in pBluescript, as template for the T3/T7 polymerase system of Stratagene. The RNA was labelled using the DIG RNA Labeling Kit from Roche. Northern hybridization was generally carried out as described by Ausubel et al. (1988), but the hybridization solution contained $10 \%$ (w/v) dextran sulfate (Sigma), $1 \%(\mathrm{w} / \mathrm{v})$ SDS, and $0.5 \%(\mathrm{w} / \mathrm{v})$ skim milk powder.

Isolation of proteins, Western analysis and production of antisera. Total proteins from various $H f$. volcanii transformants were isolated from exponential-phase ${\left(\mathrm{OD}_{600}\right.}_{0 \cdot 3-}$ $0 \cdot 4)$ and from stationary-phase $\left(\mathrm{OD}_{600}>2 \cdot 0\right)$ cultures. 
Samples $(25 \mathrm{ml}$ of exponential- and $3 \mathrm{ml}$ of stationary-phase cultures) were centrifuged at $12000 \mathrm{~g}$ and resuspended in $400 \mu \mathrm{l} \mathrm{TE}$ buffer containing $0 \cdot 5 \mu \mathrm{l} \mathrm{DNase} \mathrm{I}\left(1 \mathrm{mg} \mathrm{ml}^{-1}\right)$. The suspension was dialysed against $10 \mathrm{mM}$ Tris/ $\mathrm{HCl}, \mathrm{pH} 7 \cdot 2$, for $12 \mathrm{~h}$ at $4{ }^{\circ} \mathrm{C}$, and centrifuged for $20 \mathrm{~min}$ at $12000 \mathrm{~g}$ for membrane removal. The protein content was determined by the Bradford method. Ten micrograms of protein from each sample was separated on $15 \%$ Tricine SDS-polyacrylamide gels (Schägger \& von Jagow, 1987). Proteins were transferred to nitrocellulose membranes (Biotrace NT $0.45 \mu \mathrm{m}$, Pall Gelman Sciences) for $1 \mathrm{~h}$ at $100 \mathrm{~V}$ and $4{ }^{\circ} \mathrm{C}$ using the Midget Multiblot System (Pharmacia) in a buffer containing $25 \mathrm{mM}$ Tris/ $\mathrm{HCl}, \mathrm{pH} 8 \cdot 3$, and $192 \mathrm{mM}$ glycine. The filters were incubated in blocking buffer $(1 \%$ BSA, $0.1 \%$ Tween 20 in PBS) overnight at room temperature. The GvpD protein was detected by antiserum raised against His-tagged GvpD protein in a dilution of $1: 1000$ in blocking buffer for $1 \mathrm{~h}$ at room temperature. The filters were washed with blocking buffer and incubated with the second antibody. The ECL detection system (Amersham) was used to detect the hybridizing antibodies. The filters were exposed onto X-ray film for 10-15 min.

For formation of antibodies to the GvpD protein the $g v p D$ reading frame was amplified by PCR using the two oligonucleotides BamD and HinD (Table 1) and inserted into the His-tag expression vector pQE8 (Qiagen). The His-tagged fusion protein was synthesized in E. coli and purified using metal chelate chromatography. Rabbits were injected with $100 \mu \mathrm{g}$ purified protein contained in $1 \mathrm{ml}$ solution $(500 \mu \mathrm{l}$ $100 \mathrm{mM} \mathrm{Na}{ }_{2} \mathrm{HPO}_{4}, \mathrm{pH} \mathrm{8} \cdot 0$, and $500 \mu$ l Freund's adjuvant), and boostered three times after 2 weeks each (performed by Eurogentec, Seraing).

Analysis of DNA sequence data. DNA sequence determination was done according to the Sanger method using the SequiTherm EXCEL II Long-Read DNA Sequencing Kit-LC protocol (Biozym). The fragments were separated using a LICOR DNA sequencer at $1200 \mathrm{~V}, 35 \mathrm{~mA}$ and $50{ }^{\circ} \mathrm{C}$ for $7 \mathrm{~h}$. The GenBank accession number of the mc-vac sequence is X64701.

\section{RESULTS}

\section{The gvpD gene is involved in the repression of gas vesicle formation}

Hf. volcanii $\Delta \mathrm{D}$ transformants containing the mc-vac region with a $918 \mathrm{bp}$ deletion in mc-g $v p D$ overproduce gas vesicles (Englert et al., 1992b), and this $\mathrm{Vac}^{++}$ phenotype can be reverted by the addition of mc-g $v p D$ present on a second vector construct (Pfeifer et al., 1994). To investigate the cause of the reduction of gas vesicle formation in $\Delta \mathrm{D} / \mathrm{D}_{\text {native }}$ transformants in more detail, different mc-g $v p D$ variants were constructed (see Fig. 1). The mc-gvpD/pMDS20 construct contained the mc-gvpD gene including the endogenous promoter; this construct had been used for the initial $\Delta \mathrm{D} / \mathrm{D}$ transformant (Pfeifer et al., 1994). mc-gvp $\Delta \mathrm{D} / \mathrm{pMDS} 20$ was the same construct, but had a $918 \mathrm{bp} \mathrm{XhoI} \mathrm{deletion} \mathrm{in}$ mc- $g v p D$ (encoding non-functional GvpD), mc-gvpD/ pJAS35 harboured the mc-g $v p D$ reading frame expressed by the strong $f d x$ promoter, and the $\mathrm{mcD}$ construct contained the mc-vac promoter region plus $111 \mathrm{bp}$ derived from the $5^{\prime}$ part of mc-gvpD (Fig. 1). Transformants of $H f$. volcanii were constructed containing $\Delta \mathrm{D}$ and one of these various $\mathrm{D}$ constructs, and the Vac phenotype was inspected on agar plates. $H f$. volcanii lacks gas vesicles and forms red translucent colonies, whereas those of $\Delta \mathrm{D}$ transformants are turbid white (gas vesicle overproduction, $\mathrm{Vac}^{++}$) (Englert et al., 1992b; Fig. 2, top row). $\Delta \mathrm{D} / \mathrm{D}_{\text {native }}$ transformants form pink colonies due to a normal amount of gas vesicles $\left(\mathrm{Vac}^{+}\right)$, similar to mc-vac transformants (Fig. 2). The cells of the transformants can also be inspected by phase-contrast microscopy, where gas vesicles are seen as light-refractile particles inside the cells. $\Delta \mathrm{D}$ cells appear as bright white spheres completely filled with

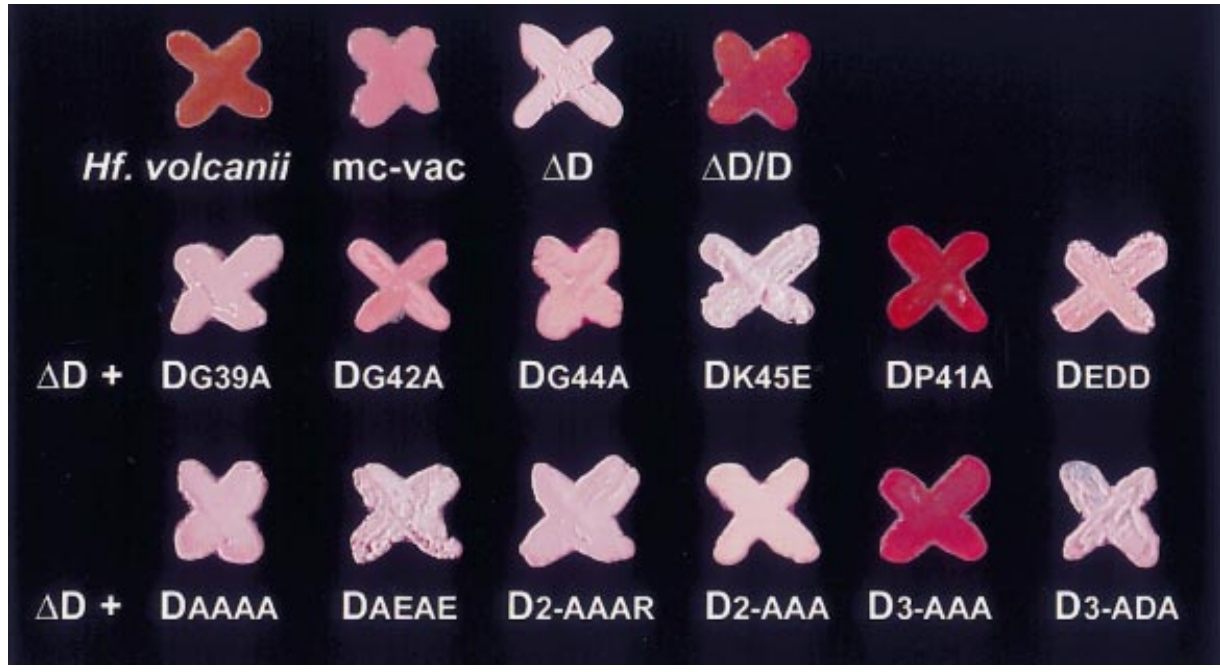

Fig. 2. Vac phenotypes of Hf. volcanii transformants on agar plates. The top row shows colonies of $H f$. volcanii and control transformants. Gas vesicle overproducing $\left(\mathrm{Vac}^{++}\right)$colonies $(\Delta \mathrm{D})$ are pink-white and opaque, $\mathrm{Vac}^{+}$colonies (mc-vac) are pink and turbid, and gas vesicle negative $\left(\mathrm{Vac}^{-}\right)$colonies ( $H f$. volcanii or $\left.\Delta \mathrm{D} / \mathrm{D}\right)$ are red and translucent. The middle row shows colonies of transformants containing $\Delta D / D_{\text {mut }}$ constructs with mutations in the p-loop region, whereas the bottom row shows colonies harbouring $\Delta D / D_{\text {mut }}$ constructs with mutations in one of the two basic regions of GvpD. 


\begin{tabular}{|c|c|c|c|c|}
\hline & & mutations & designation & $\begin{array}{l}\text { Vac phenotype } \\
\text { of } \Delta \mathrm{D} / \mathrm{D} \text { or } \Delta \mathrm{D} / \mathrm{Dm} \text { t } \\
\text { transformants }\end{array}$ \\
\hline p-loop region: & 36 & $\begin{array}{l}\text { LVNGAPGTGKT } \\
\ldots \text { A. } \\
\ldots \ldots \ldots \\
\ldots \ldots \ldots \text { A. } \\
\ldots \ldots \ldots \ldots \text { E. } \\
\ldots \ldots \text { A..... } \\
\ldots \text { E.D.D. }\end{array}$ & $\begin{array}{l}\text { D } \\
\text { DG39A } \\
\text { DG42A } \\
\text { DG44A } \\
\text { DK45E } \\
\text { DP41A } \\
\text { DEDD }\end{array}$ & $\begin{array}{l}- \\
++ \\
++ \\
++ \\
++ \\
+ \\
++\end{array}$ \\
\hline basic region 1: & 201 & 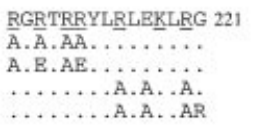 & $\begin{array}{l}\text { D } \\
\text { DAAAA } \\
\text { DAEAE } \\
\text { D2-AAA } \\
\text { D2-AAAR }\end{array}$ & $\begin{array}{l}- \\
++ \\
++ \\
++ \\
++\end{array}$ \\
\hline basic region 2: & 492 & $\begin{array}{l}\text { ELRRRADR } 499 \\
\ldots \text { ARA. } \ldots \\
\ldots \text { ADA. . }\end{array}$ & $\begin{array}{l}\text { D } \\
\text { D3-AAA } \\
\text { D3-ADA }\end{array}$ & $\begin{array}{l}- \\
+ \\
++\end{array}$ \\
\hline
\end{tabular}

Fig. 3. Mutations in the p-loop and the two basic regions. The designations of the respective mutant constructs are given, and the Vac phenotype of the transformants is indicated.

light-refractile bodies, whereas $H f$. volcanii cells are discoid (Pfeifer et al., 1994).

As expected, the control transformants $\Delta \mathrm{D}$ plus the 'empty' vector pMDS20 (or pJAS35) were $\mathrm{Vac}^{++}$, whereas the addition of mc-g $v p D / p M D S 20$ (native GvpD) revealed $\mathrm{Vac}^{+}$transformants (Pfeifer et al., 1994). The $\Delta \mathrm{D} / \mathrm{mc}-g v p \Delta \mathrm{D}$ (which encodes non-functional GvpD) and the $\Delta \mathrm{D} / \mathrm{mcD}$ (promoter region) transformants were both $\mathrm{Vac}^{++}$, demonstrating that a defective GvpD, or additional copies of mc-vac promoter (which could compete for the GvpE activator protein), did not reduce the amount of gas vesicles in the $\Delta \mathrm{D}$ transformants (Fig. 2, and data not shown). In contrast, the colonies of $\Delta \mathrm{D}$ transformants containing mc-gvpD/ pJAS35, where the $f d x$ promoter promotes large amounts of mc- $g \nu p D$ transcripts, were red, transparent and without gas vesicles $(\Delta \mathrm{D} / \mathrm{D}$, Fig. 2 , top row). These results demonstrated that the mc-gvpD reading frame, and thus the GvpD protein, was the reason for the reduced amount of gas vesicles.

The amino acid sequence of GvpD indicates three interesting regions that could be important for the repressor function: a putative p-loop motif located near the N-terminus (positions 36-46), and two basic regions (positions 201-222 and 494-499) that might function in DNA binding. These three regions were mutagenized and tested in $\Delta \mathrm{D} / \mathrm{D}_{\text {mut }}$ double transformants for their ability to reduce gas vesicle formation.

\section{Importance of the p-loop motif for the GvpD repressor function}

The putative p-loop motif in GvpD has the sequence ${ }_{36}$ LVNGAPGTGKT $_{46}$ (Fig. 3). The codons encoding the conserved amino acids (underlined) were altered by site-directed PCR mutagenesis, and inserted into the vector pJAS35 for expression under $f d x$ promoter control. $\Delta \mathrm{D} / \mathrm{D}_{\text {mut }}$ double transformants were produced and tested for the ability to reduce gas vesicle over- production. If the mutant $\mathrm{GvpD}$ proteins were unable to reduce gas vesicle formation in the $\Delta \mathrm{D}$ transformant, the altered amino acids were important for the GvpD repressor function.

gvpD mutant genes were constructed encoding $\mathrm{GvpD}_{\text {mut }}$ proteins with a G39A, G42A, G44A or K45E mutation (Fig. 3). In addition, a gvpD mutant was produced encoding GvpD that contained an alteration of the nonconserved proline $\mathrm{P} 41$ residue to an alanine. A sixth g $v p D$ mutant was obtained using a degenerate primer for PCR mutagenesis: the $\mathrm{GvpD}_{\text {mut }}$ encoded contained three alterations in the p-loop motif, namely G39E, G42D and G44D ( $D_{\mathrm{EDD}}$; Fig. 3). Each alteration in mcgupD was confirmed by DNA sequence analyses. The mutated reading frames were then transferred into the expression vector pJAS35 and used to transform $\Delta \mathrm{D}$ transformants. As control, the $\Delta \mathrm{D}$ transformant was complemented with the mc-gvpD/pJAS35 construct. Transformants appeared after 5-7 d on agar plates and were inspected for gas vesicle formation (Fig. 2). As expected, the $\Delta \mathrm{D} / \mathrm{D}$ transformants formed red and translucent colonies (Fig. 2, top row). The $\Delta \mathrm{D} / \mathrm{D}_{\text {mut }}$ transformants $\Delta \mathrm{D} / \mathrm{D}_{\mathrm{G} 39 \mathrm{~A}}, \Delta \mathrm{D} / \mathrm{D}_{\mathrm{G} 42 \mathrm{~A}}, \Delta \mathrm{D} / \mathrm{D}_{\mathrm{G} 44 \mathrm{~A}}, \Delta \mathrm{D} /$ $\mathrm{D}_{\mathrm{K} 45 \mathrm{E}}$ and $\Delta \mathrm{D} / \mathrm{D}_{\mathrm{EDD}}$ (each mutation encodes GvpD protein altered in conserved amino acids of the p-loop motif) were $\mathrm{Vac}^{++}$, implying that all these $\mathrm{GvpD}_{\text {mut }}$ proteins were unable to repress gas vesicle overproduction (Fig. 2, middle row). Only the $\Delta \mathrm{D} / \mathrm{D}_{\mathrm{P} 41 \mathrm{~A}}$ transformant was $\mathrm{Vac}^{-}$, suggesting that the GvpD protein that had incurred an exchange of the nonconserved P41 to alanine was still functional (Fig. 2).

Northern analyses were performed to ensure that each mutated mc-gvpD gene was indeed transcribed. Total RNA was isolated during the exponential and stationary growth phases of the transformants and the $918 \mathrm{bp}$ internal XhoI fragment derived from mc-g $\nu p D$ was used as probe, since it is absent in the $\Delta \mathrm{D}$ construct and hybridizes only with transcripts derived from the entire mc-g $v p D$ reading frame (see Fig. 1). RNA of Hf. volcanii WFD11 (containing no mc-vac sequences) and of the $\Delta \mathrm{D}$ transformant did not indicate any transcripts, whereas the $\mathrm{mc}$ transformant (containing the mc-vac region) indicated the expected mc-gvpD transcripts (Fig. 4a, top). The RNA of each double transformant contained mc-gvpD transcripts that were slightly smaller due to the lack of the 83 nucleotide mRNA leader that was cut off during the fusion of the reading frame to the $f d x$ promoter in the vector pJAS35. The $0.3 \mathrm{~kb}$ mc-gvpD transcript occurred in stationary growth phase only (Fig. 4a), similar to the $0.45 \mathrm{~kb}$ transcript of the mc-vac region in Hf. mediterranei (Röder \& Pfeifer, 1996). These Northern analyses demonstrated that each of the mc-g $v p D$ reading frames in pJAS35 was transcribed.

The presence of the GvpD protein in these transformants was assessed by Western analysis using a GvpD-specific antiserum (Fig. 4b). The antiserum reacted with the Histagged, $60 \mathrm{kDa}$ GvpD protein isolated from E. coli, and also with the GvpD protein in lysates of the $\Delta \mathrm{D} / \mathrm{D}$ 


\section{(a)}

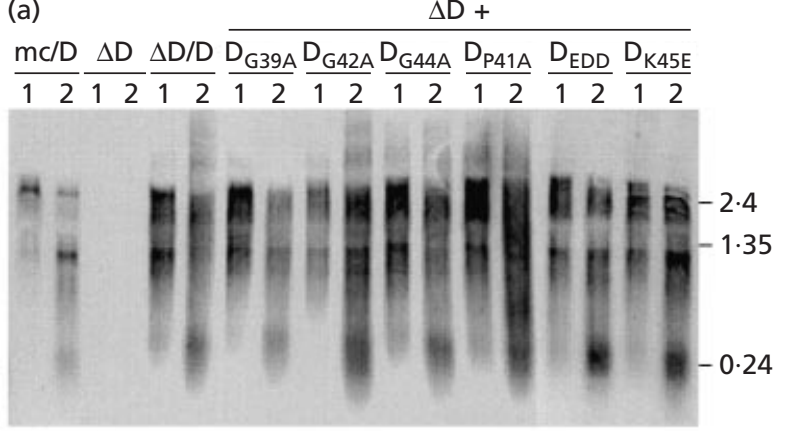

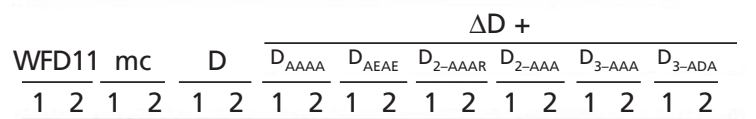

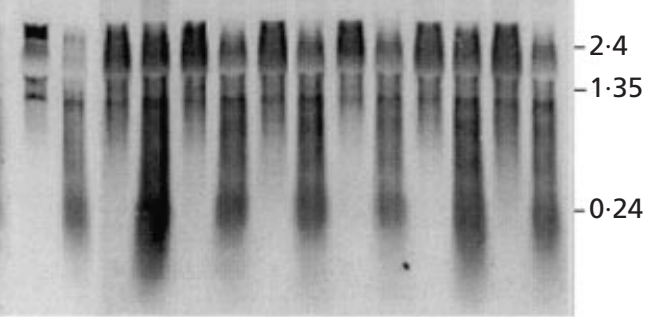

(b) $\quad \Delta \mathrm{D}+$
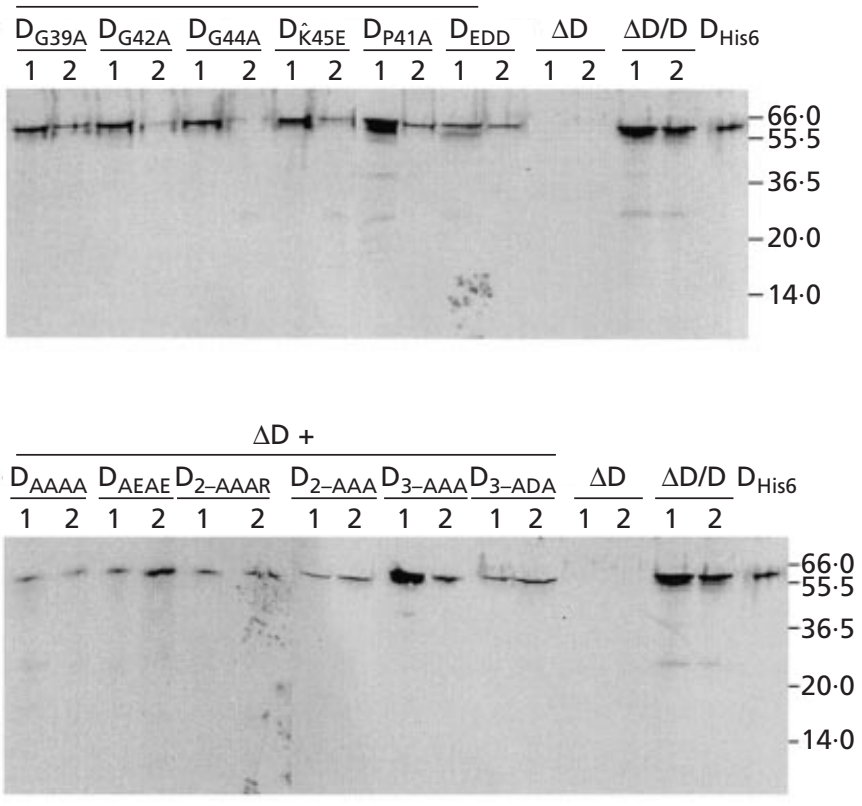

Fig. 4. (a) Northern analyses to assess the transcription of the mc-gvpD reading frame in pJAS35. Total RNA from Hf. volcanii WFD11 and from the various transformants isolated during the exponential (1) and stationary (2) growth phase was separated on $1.2 \%$ agarose gels. The designation of the constructs contained in the various transformants is given on top. Northern analyses were done with $5 \mu \mathrm{g}$ (upper blot) or $10 \mu \mathrm{g}$ (lower blot) RNA per sample. A $918 \mathrm{bp}$ Xhol fragment derived from the mc-gvpD gene was used as probe. The RNA marker sizes (in kb) are given on the right. (b) Western analyses to confirm the presence of the GvpD protein in the transformants. Proteins were isolated from the various transformants during the exponential (1) and stationary (2) growth phase. Ten microgram samples of total protein from cytoplasmic fractions was separated on $15 \%$ Tricine SDS-polyacrylamide gels, blotted onto nylon membrane and hybridized with the GvpD-specific antiserum as described. The protein marker sizes (in kDa) are given on the right.

transformant. No reaction was observed with proteins derived from the $\Delta \mathrm{D}$ transformant, indicating that the reaction of the antiserum was specific for GvpD (Fig. $4 \mathrm{~b})$. Each of the $\Delta \mathrm{D} / \mathrm{D}_{\text {mut }}$ transformants tested contained the $60 \mathrm{kDa} \mathrm{GvpD}_{\text {mut }}$ protein, demonstrating that all mc-gvpD mRNAs were indeed translated and that the GvpD protein was present in the cells. Thus, each Vac phenotype observed with the transformants was due to the $\mathrm{GvpD}_{\text {mut }}$ protein.

\section{Importance of the two basic regions for the GvpD repressor function}

Two conserved basic regions located in the GvpD sequence at position 201-215 (region 1) and position 494-499 (region 2) were also altered. Mutations in region 1 resulted in the mutant proteins $\mathrm{D}_{\mathrm{AAAA}}, \mathrm{D}_{\mathrm{AEAE}}$ and $\mathrm{D}_{2-\mathrm{AAA}}$, and mutations in region 2 resulted in the $\mathrm{D}_{\text {3-AAA }}$ protein (Fig. 3). Two additional alterations in mc-g $\nu p D$ were obtained by chance and led to an alteration of the amino acid residues $\mathrm{G} 215 \mathrm{R}\left(\mathrm{D}_{2-\mathrm{AAAR}}\right)$ and R495D ( $\left.\mathrm{D}_{3-\mathrm{ADA}}\right)$ in GvpD (Fig. 3). Each of these mutated mc-gvpD fragments was inserted into pJAS35, and the resulting constructs were used to transform $\Delta \mathrm{D}$ transformants. The phenotype of each $\Delta \mathrm{D} / \mathrm{D}_{\text {mut }}$ double transformant was again monitored by inspecting the colonies on agar plates (Fig. 2, bottom row). None of the GvpD mutants $\mathrm{D}_{\mathrm{AAAA}}, \mathrm{D}_{\mathrm{AEAE}}, \mathrm{D}_{\text {2-AAA }}, \mathrm{D}_{2-\mathrm{AAAR}}$ and $\mathrm{D}_{3-\mathrm{ADA}}$ was able to reduce the $\mathrm{Vac}^{++}$phenotype of $\Delta \mathrm{D} / \mathrm{D}_{\text {mut }}$ to $\mathrm{Vac}^{-}$, indicating that these $\mathrm{GvpD}$ mutants were unable to repress gas vesicle formation. In contrast, the $\mathrm{D}_{3-\mathrm{AAA}}$ protein was active in repression, since the $\Delta \mathrm{D} / \mathrm{D}_{3 \text {-AAA }}$ transformant did not contain gas vesicles (Fig. 2). The transcription of the mc-g $v p D$ reading frame in PJAS35 was again analysed by Northern analysis to ensure the expression of each construct (Fig. 4a, bottom). In each case, mc-g $v p D$ transcripts of $0 \cdot 3,1 \cdot 2$ and $3.0 \mathrm{~kb}$ were detected. Western analysis using the GvpD-specific antiserum indicated that GvpD (or $\mathrm{GvpD}_{\text {mut }}$ ) proteins were present in each transformant (Fig. 4b, bottom).

\section{Effect of $\mathrm{GvpD}_{\text {mut }}$ on the mcA promoter activity}

The effect of the g $v p D$ mutations on the reduction of the gas vesicle formation could occur at the mcA promoter level. Northern analyses were carried out to investigate the amount of transcripts starting at the mcA promoter present in the $\Delta \mathrm{D}$ construct during the growth of each 

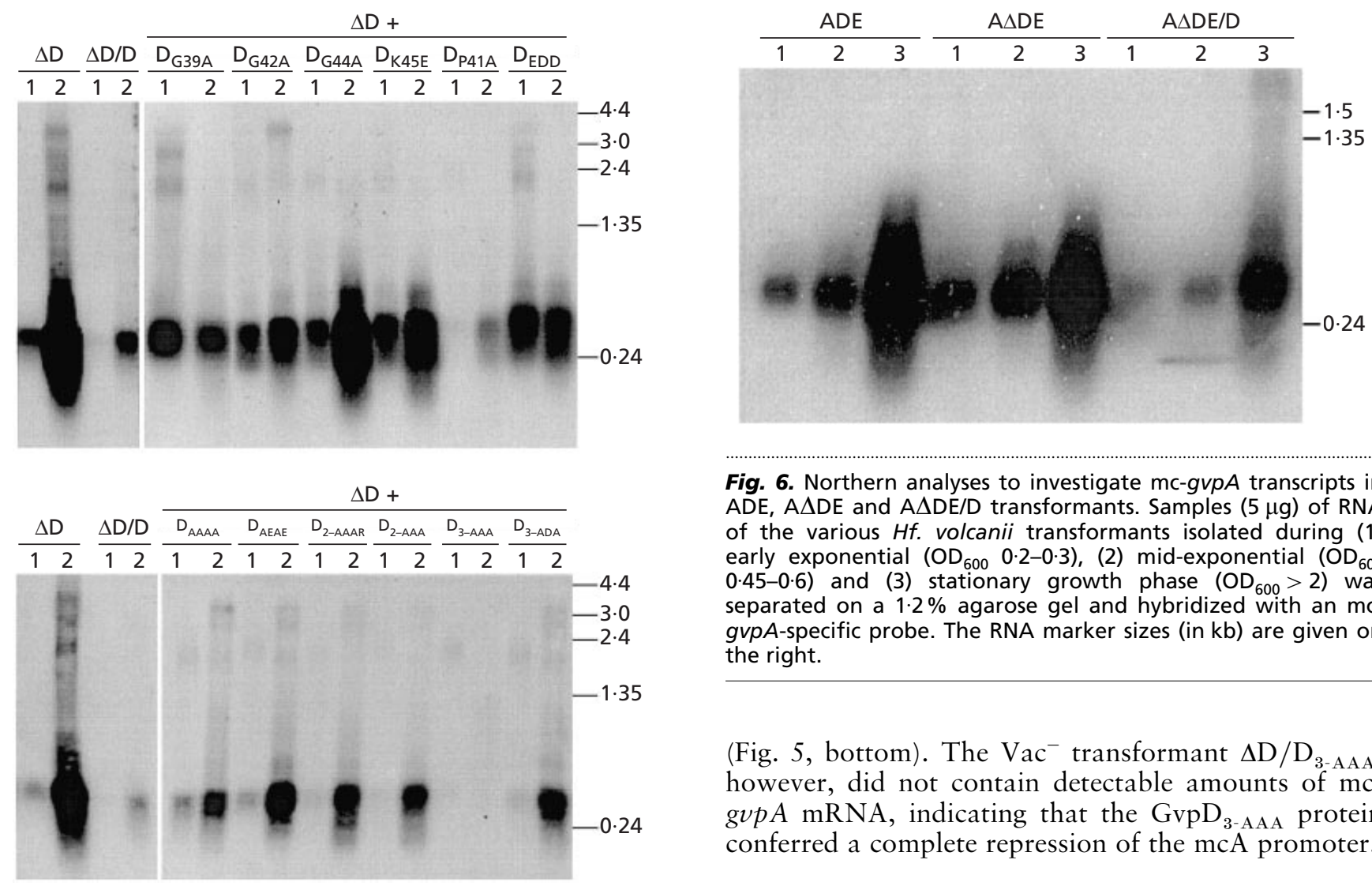

Fig. 6. Northern analyses to investigate mc-gvpA transcripts in $A D E, A \Delta D E$ and $A \Delta D E / D$ transformants. Samples $(5 \mu \mathrm{g})$ of RNA of the various $H f$. volcanii transformants isolated during (1) early exponential $\left(\mathrm{OD}_{600} 0 \cdot 2-0 \cdot 3\right)$, (2) mid-exponential $\left(\mathrm{OD}_{600}\right.$ $0 \cdot 45-0.6)$ and (3) stationary growth phase $\left(\mathrm{OD}_{600}>2\right)$ was separated on a $1.2 \%$ agarose gel and hybridized with an mcgvpA-specific probe. The RNA marker sizes (in kb) are given on the right.

Fig. 5. Northern analyses to investigate mc-gvpA transcripts in $\Delta \mathrm{D}, \Delta \mathrm{D} / \mathrm{D}$, and the various $\Delta \mathrm{D} / \mathrm{D}_{\text {mut }}$ transformants. Samples $(5 \mu \mathrm{g})$ of RNA of the various transformants isolated during the exponential (1) and stationary (2) growth phase were separated on $1.2 \%$ agarose gels and hybridized with an mc-gvpA-specific probe. The RNA marker sizes (in kb) are given on the right. The exposure times of the upper and lower blots are slightly different, as visible for the control transformants $\Delta \mathrm{D}$ and $\Delta \mathrm{D} / \mathrm{D}$ shown on the left.

transformant (Fig. 5). The $\Delta \mathrm{D}$ transformant contains high amounts of the $0.32 \mathrm{~kb}$ mc-gvpA mRNA, especially during the stationary growth phase. In the $\triangle \mathrm{D} / \mathrm{D}$ transformant, the overall amount of mc-gvpA mRNA was significantly reduced, suggesting that GvpD is directly or indirectly involved in the regulation of the mcA promoter activity (Fig. 5, top and bottom). Inspection of the mc-gvpA transcripts in $\Delta \mathrm{D} / \mathrm{D}_{\text {mut }}$ transformants containing mutations in the p-loop motif of GvpD revealed high amounts of the mc-gvpA transcripts during all growth phases in each $\mathrm{Vac}^{++}$ transformant (Fig. 5, top). In contrast, the $\mathrm{Vac}^{-}$transformant $\triangle \mathrm{D} / \mathrm{D}_{\mathrm{P} 41 \mathrm{~A}}$ showed strongly reduced amounts of mc-gvpA mRNA, similar to $\Delta \mathrm{D} / \mathrm{D}$.

The $\Delta \mathrm{D} / \mathrm{D}_{\text {mut }}$ transformants containing mutations in the two basic regions of GvpD revealed high amounts of mc-gvpA mRNA in the stationary growth phase only. In contrast to the $\Delta \mathrm{D} / \mathrm{Dp}$-loop transformants, relatively low amounts of mc-gvpA mRNA were present during the exponential growth phase of these transformants

(Fig. 5, bottom). The $\mathrm{Vac}^{-}$transformant $\Delta \mathrm{D} / \mathrm{D}_{3-\mathrm{AAA}}$, however, did not contain detectable amounts of mcgvpA mRNA, indicating that the $\mathrm{GvpD}_{3-\mathrm{AAA}}$ protein conferred a complete repression of the $\mathrm{mcA}$ promoter.

\section{Effect of GvpD mutations on the mcA promoter on the $A \Delta D E$ construct}

To determine whether the regulation of the $\mathrm{mcA}$ promoter involves other products of $g v p$ genes besides GvpE and GvpD, we used a construct containing the mc$g v p A$ gene together with mc-gvpDE (ADE construct), and the $\mathrm{A} \triangle \mathrm{DE}$ construct, where the mc-gvpD gene had incurred the same $918 \mathrm{bp}$ internal deletion as found in $\Delta \mathrm{D}$ (Röder \& Pfeifer, 1996). ADE transformants contained high amounts of mc-gvpA mRNA, especially in the stationary growth phase, whereas slightly higher amounts of this transcript during exponential growth were observed in transformants containing the $\mathrm{A} \Delta \mathrm{DE}$ construct (Fig. 6, and Röder \& Pfeifer, 1996). The double transformant $\mathrm{A} \Delta \mathrm{DE} / \mathrm{D}$ containing the mc- $g \nu p D$ reading frame under the control of the strong $f d x$ promoter in addition to the $\mathrm{A} \triangle \mathrm{DE}$ construct indicated a significantly reduced amount of mc-gvpA mRNA (Fig. 6). Thus, a low mcA promoter activity can be achieved by a high expression of the mc-gvpD gene.

\section{DISCUSSION}

The results presented in this report prove that the repression of gas vesicle formation in $\Delta \mathrm{D} / \mathrm{D}$ transformants was caused by the GvpD protein and not by the additional mc-vac promoter sequences that could compete for the GvpE activator. The strong $f d x$ promoter in the expression vector pJAS35 presumably led to high amounts of GvpD that were sufficient to abolish gas vesicle formation, whereas the addition of the mc- 
$g v p D$ gene under endogenous promoter control resulted in a gas vesicle level as observed in the wild-type (Pfeifer et al., 1994, and this report).

\section{The p-loop motif and basic regions of GvpD are required for the repressing function}

Various mutant GvpD proteins were designed to investigate the importance of these conserved regions with respect to the GvpD repressor function. Each mutation of a conserved residue (G39A, G42A, G44A or K45E) in the $\mathrm{p}$-loop region resulted in an inactive GvpD protein when tested in $\Delta \mathrm{D} / \mathrm{D}_{\text {mut }}$ double transformants. In contrast, $\mathrm{GvpD}_{\text {mut }}$ proteins with an alteration of the unconserved proline residue $\mathrm{P} 41 \mathrm{~A}$ within the p-loop region were still able to repress the gas vesicle formation in $\Delta \mathrm{D} / \mathrm{D}_{\mathrm{P} 41 \mathrm{~A}}$ transformants. These results imply that ATP- or GTP-binding and hydrolysis might be important for the repressor function of GvpD, and experiments are under way to proof that GvpD can indeed bind mononucleotides.

Similar investigations of mutations in two basic regions in GvpD demonstrated that the exchange of arginine and lysine residues in basic region 1 completely abolished the repressing function: the GvpD mutants $\mathrm{D}_{\mathrm{AAAA}}, \mathrm{D}_{\mathrm{AEAE}}$ and $\mathrm{D}_{2-\mathrm{AAA}}$ were unable to reduce the amount of gas vesicles in $\Delta \mathrm{D} / \mathrm{D}_{\text {mut }}$ transformants. This basic region 1 might be involved in DNA binding of GvpD; this needs to be investigated in more detail. In contrast, the alterations introduced in basic region 2 $\left({ }_{494} R_{R R}{ }_{496}\right)$ revealed ambiguous results: an alteration of RRR to AAA revealed a $G_{v p D}$ mut protein that still functioned in repression. Since a positive charge in this region was obviously not required for the repressor function, this result suggested that region 2 is not involved in DNA binding. In contrast, changing the RRR to ADA residues and introduction of a negatively charged amino acid abolished the GvpD repressor function.

\section{GvpD is involved in the reduction of the amount of mc-gvpA mRNA}

The question whether GvpD is acting as repressor at the transcriptional level was further addressed by studying the effect of $g v p D$ mutations on the activity of the mcA promoter. $\triangle \mathrm{D}$ transformants contain high amounts of mc-gvpA mRNA, especially during stationary growth (Englert et al., 1992b; Röder \& Pfeifer, 1996). Northern analyses indicated that the presence of the native $g v p D$ gene in $\Delta \mathrm{D} / \mathrm{D}_{\text {native }}$ transformants resulted in a drastic reduction of the amount of mc-gvpA mRNA. The same reduction was seen with the $\operatorname{Vac}^{-} \Delta \mathrm{D} / \mathrm{D}_{\text {mut }}$ transformants encoding the GvpD proteins $\mathrm{D}_{\mathrm{P} 41 \mathrm{~A}}$ or $\mathrm{D}_{3-\mathrm{AAA}}$. The $\Delta \mathrm{D} / \mathrm{D}_{3-\mathrm{AAA}}$ transformant even completely lacked mc-gvpA mRNA, suggesting that this mc-gvpD mutation gave rise to a 'super'-repressor. In contrast, the $\mathrm{D}_{3-\mathrm{ADA}}$ protein containing an aspartate in place of an alanine was inactive with respect to repression of the mcA promoter.
Different results were observed with the various $g v p D_{\text {mut }}$ genes that were unable to reduce the $\mathrm{Vac}^{++}$phenotype in transformants. Despite the $\mathrm{Vac}^{++}$phenotype, the mRNA patterns differed from that observed for the $\Delta \mathrm{D}$ transformant. Transformants producing $\mathrm{GvpD}_{\text {mut }}$ with alterations in the p-loop motif indicated significantly higher amounts of mc-gvpA mRNA during exponential growth, and the mcA promoter remained similarly active during stationary growth. The overproduction of gas vesicles in these transformants was possibly due to the early activation of the mcA promoter. Taking into account that the GvpD protein by itself cannot activate the mcA promoter (since the $\mathrm{AD}$ construct does not enable the cell to produce mc-gvpA mRNA; Röder \& Pfeifer, 1996), this result must be due to the action of the GvpE activator, and this activation occurs earlier in these transformants compared to the mcA promoter activation in $\Delta \mathrm{D}$ transformants. In contrast, alteration of a non-conserved amino acid in the p-loop region had no effect on the GvpD function. These results suggested that nucleotide binding (and hydrolysis?) was required to prevent the activation of the mcA promoter by GvpE during exponential growth. The $\mathrm{Vac}^{++}$transformants containing mc-g $\nu p D$ genes encoding proteins with mutations in the basic regions showed a slight reduction in the mc-gvpA amount compared to $\Delta \mathrm{D}$, but this amount of mRNA was still enough to reveal the overproduction of gas vesicles in these transformants.

The effect of mc-g $v p D$ mutations on the mcA promoter was also studied in $\mathrm{ADE}, \mathrm{A} \triangle \mathrm{DE}$ and $\mathrm{A} \triangle \mathrm{DE} / \mathrm{D}$ transformants to determine whether additional $g \nu p$ genes are involved. While the amount of mc-gvpA mRNA was high in $\mathrm{A} \triangle \mathrm{DE}$ and only slightly lower in ADE transformants, the amount of this transcript was significantly reduced by the addition of the mc-g $v p D$ gene under $f d x$ promoter control in the $\mathrm{A} \Delta \mathrm{DE} / \mathrm{D}$ double transformant. This result is most likely due to an earlier and stronger synthesis of GvpD compared to the ADE transformants. These data imply that the repressing function of GvpD involved no additional Gvp proteins (besides possibly GvpE). It is not known, so far, whether GvpD acts directly or indirectly at the mcA promoter, since it is also possible that GvpD inactivates GvpE (depending on a functional p-loop) or acts at the mRNA level by reducing the amount of GvpE produced during exponential growth.

\section{ACKNOWLEDGEMENTS}

This work received financial support from the Deutsche Forschungsgemeinschaft (Pf 165/6-3 and 165/8-1). We thank Jobst Gmeiner for critical reading of this manuscript. Lovastatin (a derivative of mevinolin) was a generous gift of MSD Sharp \& Dohme GmbH (München).

\section{REFERENCES}

Ausubel, F. M., Brent, R., Kingston, R. E., Moore, D. D., Seidman, J. G., Smith, J. A. \& Struhl, K. (1988). Current Protocols in Molecular Biology, vol. 1. New York: Greene Publishing Associates and Wiley-Interscience. 
Chomczynski, P. \& Sacchi, N. (1987). Single step method of RNA isolation by acid guanidinium thiocyanate-phenol-chloroform extraction. Anal Biochem 162, 156-159.

Cohen-Kupiec, R., Blank, C. \& Leigh, J. A. (1997). Transcriptional regulation in Archaea: in vivo demonstration of a repressor binding site in a methanogen. Proc Natl Acad Sci USA 94, 1316-1320.

DasSarma, S., Arora, P., Lin, F., Molinari, E. \& Yin, L. (1994). Wildtype gas vesicle formation requires at least ten genes in the gvp gene cluster of Halobacterium halobium plasmid pNRC100. J Bacteriol 176, 7646-7652.

Deyrup, A., Krishnan, S., Cockburn, B. N. \& Schwatz, N. B. (1998). Deletion and site-directed mutagenesis of the ATP-binding motif (p-loop) in the bifunctional murine ATP-sulfurylase/adenosine 5'-phosphosulfate kinase enzyme. J Bacteriol 273, 9450-9456.

Ellenberger, T. E., Brandl, C. J., Struhl, K. \& Harrison, S. C. (1992). The GCN4 basic region leucine zipper binds DNA as a dimer of uninterrupted a helices: crystal structure of the protein-DNA complex. Cell 71, 1223-1237.

Englert, C. \& Pfeifer, F. (1993). Analysis of gas vesicle gene expression in Haloferax mediterranei reveals that GvpA and GvpC are both gas vesicle structural proteins. J Biol Chem 268, 9329-9336.

Englert, C., Horne, M. \& Pfeifer, F. (1990). Expression of the major gas vesicle protein in the halophilic archaebacterium Haloferax mediterranei is modulated by salt. Mol Gen Genet 222, 225-232.

Englert, C., Krüger, K., Offner, S. \& Pfeifer, F. (1992a). Three different but related gene clusters encoding gas vesicles in halophilic archaea. J Mol Biol 227, 586-592.

Englert, C., Wanner, G. \& Pfeifer, F. (1992b). Functional analysis of the gas-vesicle gene cluster of the halophilic archaeon Haloferax mediterranei defines the vac-region boundary and suggests a regulatory role for the g $v p D$ gene or its product. Mol Microbiol 6, 3543-3550.

Halladay, J., Jones, J., Lin, F., MacDonald, F. \& DasSarma, S. (1993). The rightward gas-vesicle operon in Halobacterium plasmid pNRC100: identification of the $g v p A$ and $g v p C$ gene products by use of antibody probes and genetic analysis of the region downstream of gvpC. J Bacteriol 175, 684-692.

Hausner, W., Wettach, J., Hethke, C. \& Thomm, M. (1996). Two transcription factors related with the eucaryal transcription factors TATA-binding protein and transcription factor IIB direct promoter recognition by an archaeal RNA polymerase. $J$ Biol Chem 27, 30144-30148.

Hayes, P. K., Buchholz, B. \& Walsby, A. E. (1992). Gas vesicles are strengthened by the outer-surface protein, GvpC. Arch Microbiol 157, 229-234.

Holmes, M. L., Nuttall, S. D. \& Dyall-Smith, M. (1991). Construction and use of halobacterial shuttle vectors and further studies on Haloferax DNA gyrase. J Bacteriol 12, 3807-3813.

Jones, J. G., Young, D. C. \& DasSarma, S. (1991). Structure and organization of the gas-vesicle gene cluster on the Halobacterium halobium plasmid pNRC100. Gene 102, 117-122.

Kinsman, R., Walsby, A. E. \& Hayes, P. K. (1995). GvpCs with reduced numbers of repeating sequence elements bind to and strengthen cyanobacterial gas vesicles. Mol Microbiol 17, 147-154.

Konola, J. T., Logan, K. M. \& Knight, K. L. (1994). Functional characterization of residues in the p-loop motif of the RecA protein ATP binding site. J Mol Biol 237, 20-34.

Krüger, K., Hermann, T., Armbruster, V. \& Pfeifer, F. (1998). The transcriptional activator GvpE for the halobacterial gas vesicle genes resembles a basic region leucine-zipper regulatory protein. J Mol Biol 279, 761-771.

Lagrange, T., Kapanidis, A., Tang, H., Reinberg, D. \& Ebright, R. (1998). New core promoter element in RNA polymerase IIdependent transcription: sequence-specific DNA binding by transcription factor IIB. Genes Dev 12, 34-44.

Lam, W. L. \& Doolittle, W. F. (1989). Shuttle vectors for the archaebacterium Halobacterium volcanii. Proc Natl Acad Sci US A 86, 5478-5482.

Ng, W. L., Ciufo, S., Smith, T. \& 9 other authors (1998). Snapshot of a large dynamic replicon in a halophilic archaeon: megaplasmid or minichromosome? Genome Res 8, 1131-1141.

Offner, S. \& Pfeifer, F. (1995). Complementation studies with the gas vesicle-encoding p-vac region of Halobacterium salinarium PHH1 reveal a regulatory role for the p-gvpDE genes. Mol Microbiol 16, 9-19.

Offner, S., Wanner, G. \& Pfeifer, F. (1996). Functional studies of the gvpACNO operon of Halobacterium salinarium reveal that the GvpC protein shapes gas vesicles. J Bacteriol 178, 2071-2078.

Offner, S., Hofacker, A., Wanner, G. \& Pfeifer, F. (2000). Eight of fourteen $g v p$ genes are sufficient for the formation of gas vesicles in halophilic archaea. J Bacteriol 182, 4328-4336.

Palmer, B. \& Marinus, M. (1994). The $d a m$ and $d c m$ strains of Escherichia coli - a review. Gene 143, 1-12.

Pfeifer, F. \& Englert, C. (1992). Function and biosynthesis of gas vesicles in halophilic archaea. J Bioenerg Biomembr 24, 577-585.

Pfeifer, F. \& Ghahraman, P. (1993). Plasmid pHH1 of Halobacterium salinarium: characterization of the replicon region, the gas-vesicle gene cluster and insertion elements. Mol Gen Genet 238, 193-200.

Pfeifer, F., Offner, S., Krüger, K., Ghahraman, P. \& Englert, C. (1994). Transformation of halophilic archaea and investigation of gas-vesicle synthesis. Syst Appl Microbiol 16, 569-577.

Qureshi, S. \& Jackson, S. (1998). Sequence-specific DNA binding by the $S$. shibatae TFIIB homolog, TFB, and its effect on promoter strength. Mol Cell 1, 389-400.

Qureshi, S., Baumann, P., Rowlands, T., Khoo, B. \& Jackson, S. (1995). Cloning and functional analysis of the TATA binding protein from Sulfolobus shibatae. Nucleic Acids Res 23, $1775-1781$.

Röder, R. \& Pfeifer, F. (1996). Influence of salt on the transcription of the gas-vesicle genes of Haloferax mediterranei and identification of the endogenous transcriptional activator gene. Microbiology 142, 1715-1723.

Rodriguez-Valera, F., Juez, G. \& Kushner, D. (1983). Halobacterium mediterranei spec. nov., a new carbohydrate-utilizing extreme halophile. Syst Appl Microbiol 4, 369-381.

Ruepp, A. \& Soppa, J. (1996). Fermentative arginine degradation in Halobacterium salinarum: genes, gene products and transcripts of the arcRACB gene cluster. J Bacteriol 178, 4942-4947.

Sambrook, J., Fritsch, E. F. \& Maniatis, T. (1989). Molecular Cloning: a Laboratory Manual, 2nd edn. Cold Spring Harbor, NY : Cold Spring Harbor Laboratory.

Saraste, M., Sibbald, P. R. \& Wittinghofer, A. (1990). The p-loop - a common motif in ATP- and GTP-binding proteins. Trends Biochem Sci 15, 430-434.

Schägger, H. \& von Jagow, G. (1987). Tricine-sodium dodecyl sulfate-polyacrylamide gel electrophoresis for the separation of proteins in the range from 1 to $100 \mathrm{kDa}$. Anal Biochem 166, $368-379$. 
Skovgaard, O., Oleson, K. \& Wright, A. (1998). The central lysine in the p-loop motif of Escherichia coli DnaA protein is essential for initiating DNA replication from the chromosomal origin, oriC, and the F-factor origin, oriS, but is dispensable for initiation from the P1-plasmid origin, oriR. Plasmid 40, 91-99.

Smith, C. A. \& Rayment, I. (1996). Active site comparisons highlight structural similarities between myosin and other p-loop proteins. Biophys J 70, 1590-1602.

Soppa, J., Link, T. A., Ruepp, A., Vatter, P. \& zur Mühlen, A. (1998). Regulation of gene expression in Halobacterium salinarum: the $\operatorname{arcRACB}$ gene cluster and the TATA box-binding protein. In Microbiology and Biogeochemistry of Hypersaline
Enviroments, pp. 249-263. Edited by A. Oren. Boca Raton, FL: CRC Press.

Thomm, M. (1996). Archaeal transcription factors and their role in transcription initiation. FEMS Microbiol Rev 18, 159-171.

Thompson, D. K., Palmer, J. R. \& Daniels, C. J. (1999). Expression and heat-responsive regulation of a TFIIB homologue from the archaeon Haloferax volcanii. Mol Microbiol 33, 1081-1092.

Walsby, A. E. (1994). Gas vesicles. Microbiol Rev 58, 94-144.

Received 20 June 2000; revised 26 September 2000; accepted 18 October 2000. 